INTERNATIONAL JOURNAL OF

MULTIDISCIPLINARY STUDIES IN ARCHITECTURE AND CULTURAL

HERITAGE

ISSN: $2735-4415$

volume 2 , issue $2,2019,1-14$.

www.egyptfuture.org/ojs/

\title{
The Significance of Ornaments and Motifs in Heritage Buildings of Alexandria, Egypt
}

\author{
Nermin Saad Fathalla a, *
}

a Lecturer, Interior Design Department, Faculty of Fine Arts, Alexandria University, Egypt

\begin{abstract}
Ornaments and motifs in architecture are elements that which added to an otherwise merely structural form, usually for the purpose of decoration or embellishment, it's the language through which architecture communicates with a public. Utilizing those decorative elements and motifs is considered as an intellectual communication throughout the characteristics of architectural styles. The importance of the study is Identifying and understanding the range of ornamental design principles used in previous times which signifies the transformations of eras. Styles of ornamentation studied in reference to the specific culture, which develops unique forms of decoration, or modified ornaments from other cultures. Very few researches have been undertaken to study such decorative elements, hence the objective of the study was to understand, record and analyze the existing wide variety of decorative ornaments, which were spread in Alexandria, mainly two distinctive styles, which were the Neoclassic, and Art Deco styles. This was done through case studies where data was collected by using survey as a main method, throughout several heritage buildings during the late 19th century and the early 20th century of cosmopolitan Alexandrian era. The research discusses these abundant vast ranges of motifs used in ornaments and embellishments which have an importance to grant an identity to buildings therefore identity of the city, also to emphasize distinctive features of elements, sometimes with no function, but exist merely to be a work of art, considered as ramifications to the past, arousing people's nostalgic feelings.
\end{abstract}

Keywords

Ornaments
Motifs
Identity
Heritage Buildings
Alexandria
Egypt




\section{Introduction}

Ornaments and motifs in architecture are elements that which added to an otherwise merely structural form, usually for the purpose of decoration or embellishment, it's the language through which architecture communicates with a public. Utilizing those decorative elements and motifs is considered as an intellectual communication throughout the characteristics of architectural styles.

The importance of the study is Identifying and understanding the range of ornamental design principles used in previous times which signifies the transformations of eras. Styles of ornamentation studied in reference to the specific culture which develops unique forms of decoration, or modified ornaments from other cultures.

Very few researches have been undertaken to study such decorative elements, hence the objective of the study was to understand, record and analyze the existing wide variety of decorative ornaments which were spread in Alexandria, mainly two distinctive styles which were the Neoclassic and Art Deco styles.

This was done through case studies where data was collected by using survey as a main method, throughout several heritage buildings during the late 19th century and the early 20th century of cosmopolitan Alexandrian era.

The research discusses these abundant vast ranges of motifs used in ornaments and embellishments which have an importance to grant an identity to buildings therefore identity of the city, also to emphasize distinctive features of elements, sometimes with no function, but exist merely to be a work of art, considered as ramifications to the past, arousing people's nostalgic feelings.

Keywords: Ornaments - Motifs - Identity - Heritage buildings - Alexandria, Egypt

\section{1- What are Ornaments and Motifs in Architecture?}

Ornaments and motifs are the language through which architecture and design communicates, it's the desire to celebrate. A formula for the use of ornaments in architecture and design must be based on the close connection of all elements that play a role emphasizing the goals and function of the construction and the meaning of order, contrast, rhythm, proportion, harmony, scale and unity of the whole and 
abstraction.

The wide range of ornaments and motifs usually used in facades of neoclassic and eclectic styles buildings such as columns capitals, pediments emphasizing entrances and windows, entablatures, cornices, friezes, architraves, panels, brackets, gratings (fer forge), balustrades, patterns, decorative reliefs and others inspired of renaissance architectural ornaments mostly like foliage and geometric patterns.

Art Deco also used, which had a mix of many different styles, united by a desire to be modern, using nature motifs like shells, flowers, geometric, angular, stepped and radiating ornaments.

\section{2- Heritage Buildings of Alexandria, Egypt}

Classical styles were wide spread to a great extent in architecture in the nineteenth century in cosmopolitan Alexandria, especially in villas and several storey buildings with a distinct identity representing time.

The research paper is concerned with buildings found in downtown of Alexandria city, where Neoclassicism was wide spread, also integration of different styles to Eclecticism such as Venetian, Revivals (Classical revival, Gothic revival, Greek revival, Neo Islamic, Neo Romanesque ...) and Art Deco Styles.

Neoclassic architecture was an architecture style produced by the neoclassical movement that began in the mid eighteenth century as a reaction against the Rococo style also outgrowing of some classicizing features of the Late Baroque. Intellectually Neoclassicism was a desire to return to the perceived "purity" of the arts of Rome, Greek and renaissance classicism. Subsequently wide spread in Egypt at the late eighteenth century and early nineteenth century.

A wide range of Neoclassical, Eclectic and Art deco ornaments and motifs were used in such buildings especially on facades. Also ornaments and motifs of Eclectic styles which were consistently subject to variation and modification, promoting variety over order, a license for invention, and an architectural classification that allowed for flexibility, expansion, and variation to conceptualization of the five orders.

\section{3- The Significance of Ornaments and Motifs in Heritage Buildings of Alexandria:}


Ornamentation is the most evident characteristic to identifying architecture, recognitionof the style identity, a visual documentation of time, emphasis of different types of architectural elements such as entrances, windows and columns, entablatures, as shown in examples of figures (1-61).

Ornaments and motifs used in heritage buildings were certainly classified in antiquityalso facilitate connectivity between different sections of a building. They also add an aesthetic value to the structure. In addition ornamentation and motifs are important aspects for revelation of feelings and reminiscences of the past times with its nostalgic ramifications.

\section{4- Research Methodology and Analysis:}

This research includes analytical descriptive study of heritage buildings' ornaments and motifs, for identifying and understanding their design principles through place, time and the different expressions they resemble.

The study focuses on ornamental elements both its inherent form and beauty, this wasdone through analyzing the historical importance of such ornaments and motifs across downtown Alexandrian heritage buildings.

\section{5- Cases Studies in Heritage Buildings of Alexandria:}

The study took place at several old streets in Alexandria Downtown such as rue Fouad, ruesheriff, the Latin District, Ramleh station District and Mansheia districts.

Architectural subjects included designs for buildings exteriors, including decorative ornaments and motifs; Styles were a range of neoclassic era, revivals in architecture such as, Gothic Revival, and Art Deco style. Data was collected by using survey as a main method, throughout several heritage buildings during the late 19th century and the early 20th century of cosmopolitan Alexandrian era. The following cases studies representing photos illustrating how wide-ranging these aesthetic concerns, Analyzing each aspect and significance.

CASE STUDIES; Figures (1 to 16) illustrates the main features and characteristics of ornamentsand motifs found on facades of heritage buildings in downtown districts of Alexandria; 

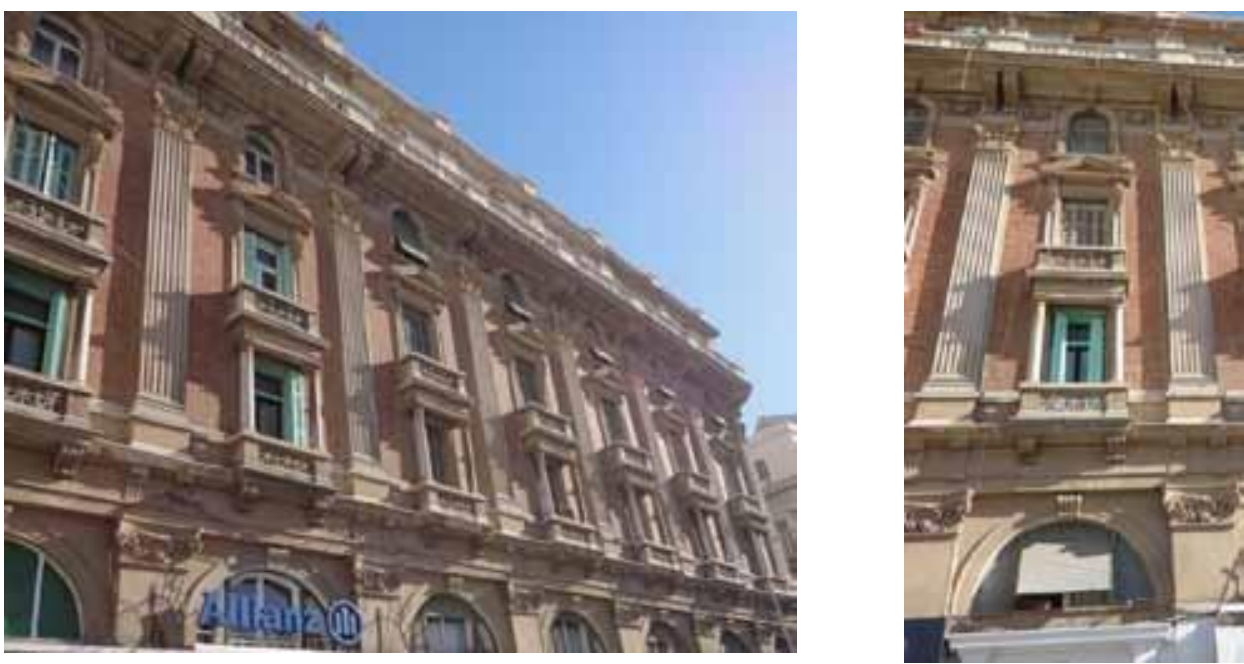

Fig.1 : Ornamental details of a Neo classic style residential/offices building façade; first level with plain shafts pedestals with ionic capitals and decorative motifs of shells and leaves, Diocletian windows with classical scroll form key stone, second level; fluted shafts pedestalswith composite capitals with acanthus leaves decorative motifs, Tuscan columns on third floor balconies, with Greek geometric pattern, triangular pediment over windows, Voluted brackets, top frieze with dentils, sculptured birds and garlands. (Fouad St.)
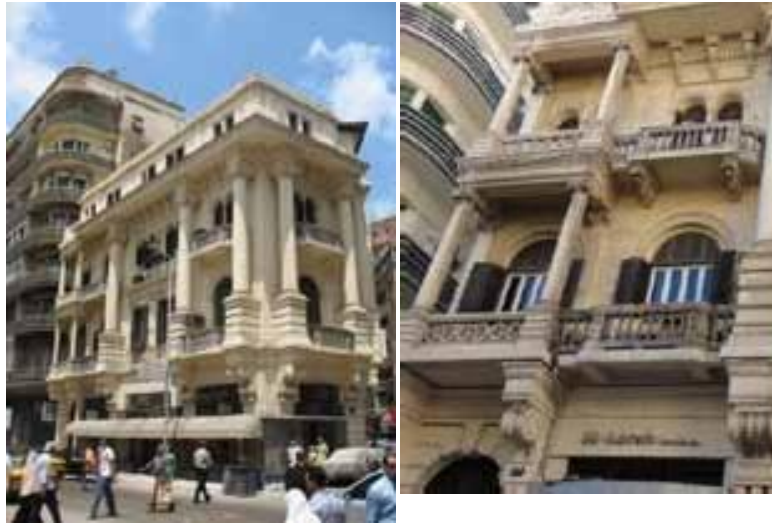

Fig. 2 : Ornamental details of a High Eclectic Mannerist building; with a mix of different styles; plain shaft Ionic columns and pilasters, egg and dart motifs resembling life and death, cornice with dentils, variety of bracket ornaments some with animals heads and some with acanthus leaves others with voluted form, balcony balustrades with columns and scroll

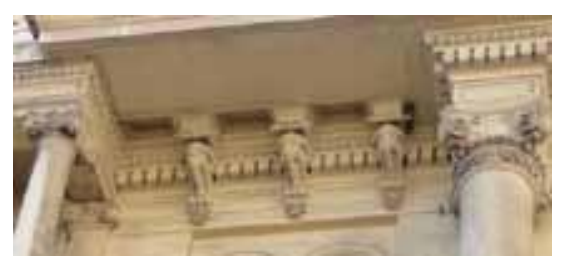


motifs, stone effect walls. (Fouad St.) (Palazzina Agion,6881) (Now a branch of AlAhram Newspaper)
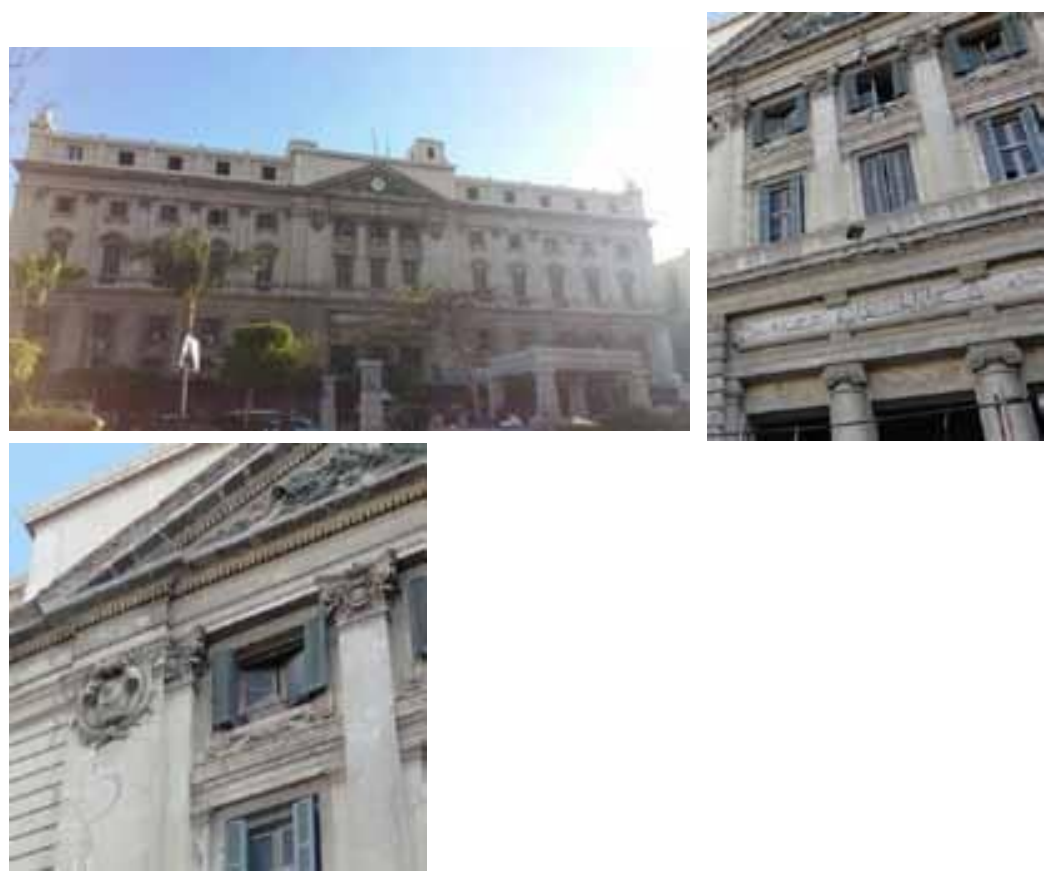

Fig. 3 : Ornamental details of a Neo classic style court house; symmetrical façade with triangular pediment containing classical motifs of foliage, plain shaft Ionic columns with voluted capitals with egg and dart motifs, composite pedestals, third storey level windows have a pediment, stone effect walls, classical balcony balustrades. (Manshieh square District)
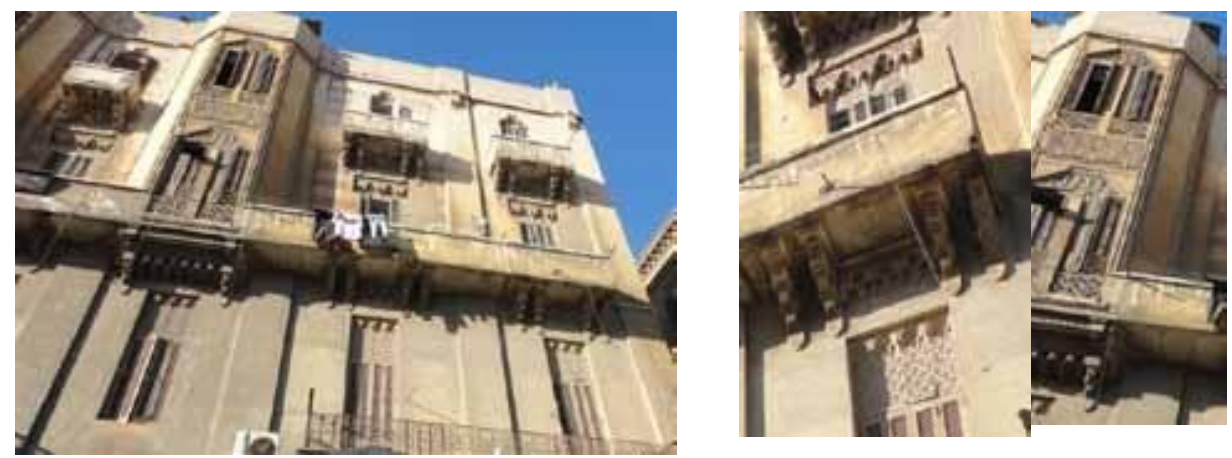

Fig. 4: Ornamental details of a Neo Islamic residential building with traditional elements of Islamic ornaments; Stalactites and brackets beneath balconies, panels 
with geometric and arabesque patterns of floral and foliage abstract forms. (Manshia District)
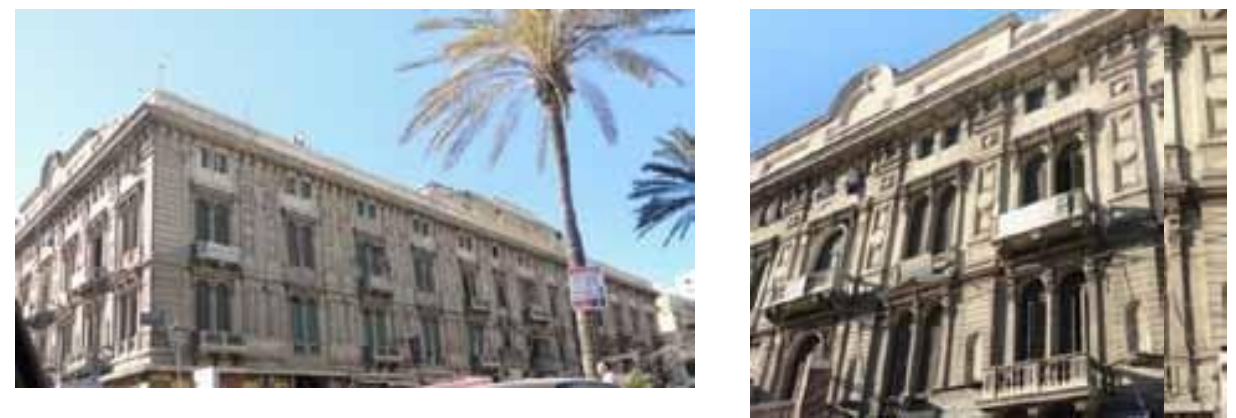

Fig. 5: Ornamental details of an Eclectic Style residential building; with a mix of different styles; classic renaissance windows some with triangular pediment and others with lintel frieze cornice, panels with geometric forms, the main frieze with volute scrolls, walls embellished with stone effect, classical balcony balustrades. (Manshia square District)
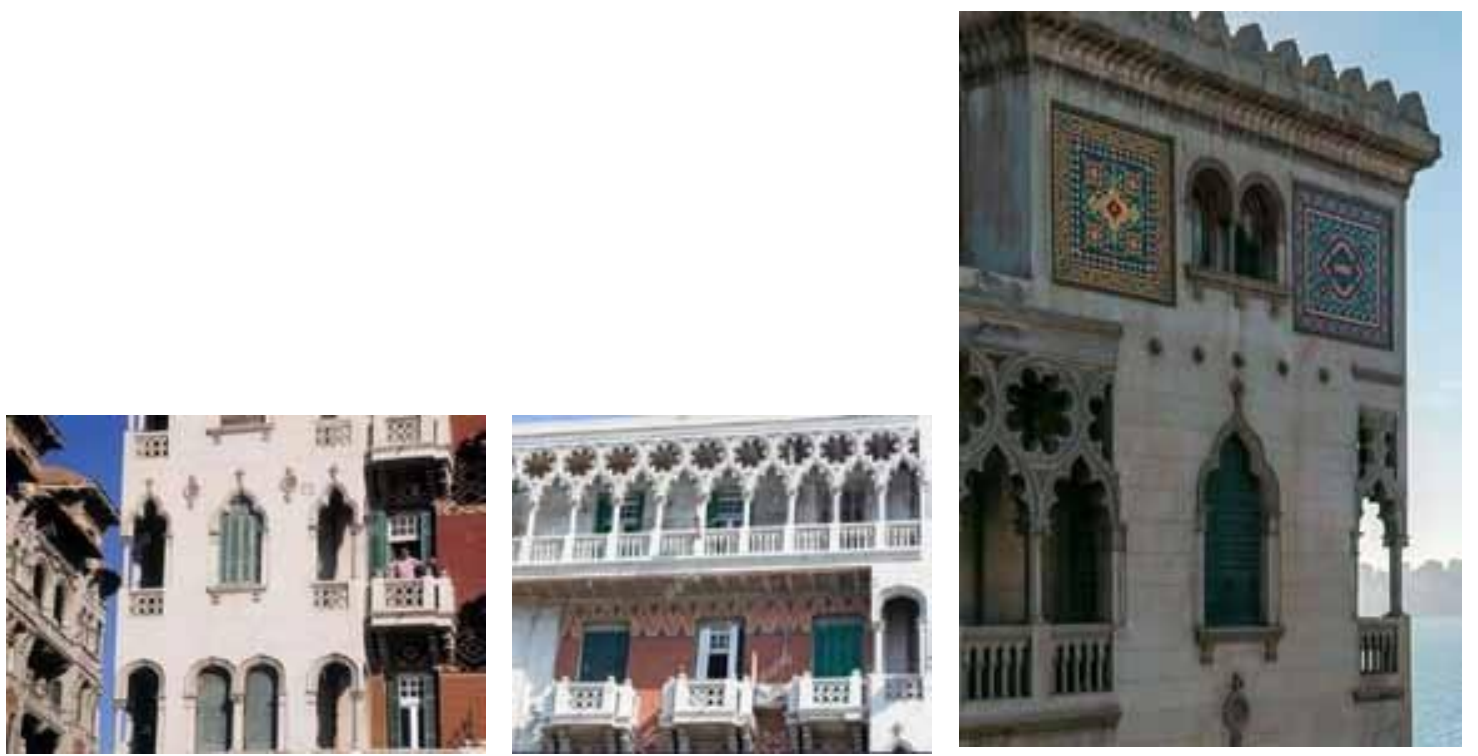

Fig. 6: Ornamental detail of Venetian Gothic Style residential building "Little Venice"; repeated pointed cinquefoil arches, rosettes and arcade of columns, various window types some withflattened pointed arch, some with trefoil arch and others are rectangular, parts of facades withstone effect or walls rich patterns, panels of 
multicolored decorative brick stones. (Raml District, Cournich Road)
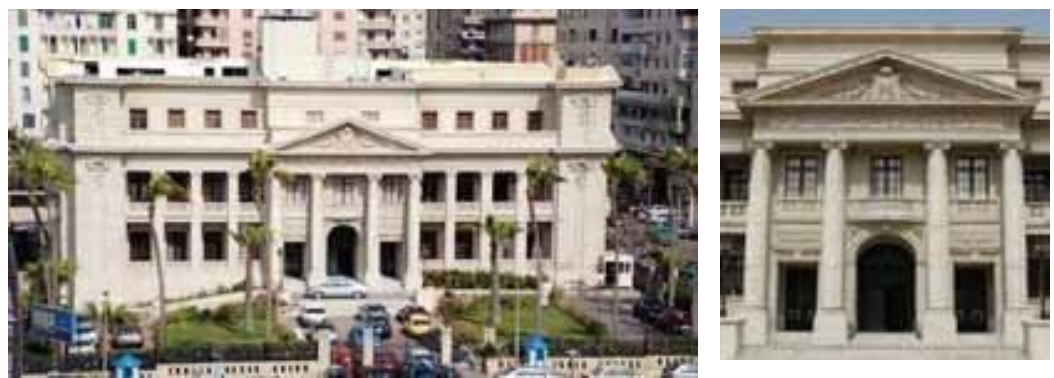

Fig.7 : Ornamental details of a Greek Revival Style villa; the main entrance accentuated with triangular pediment and entablature with classical motifs, a metope and triglyph frieze also dentils, four Ionic columns with pedestals, walls with stone effect, Greek geometric patterned balcony grills, side broken pediments centered with circular wreath with laurel leafs. (Raml District, Cournich Road) (villa now: Women public service center)
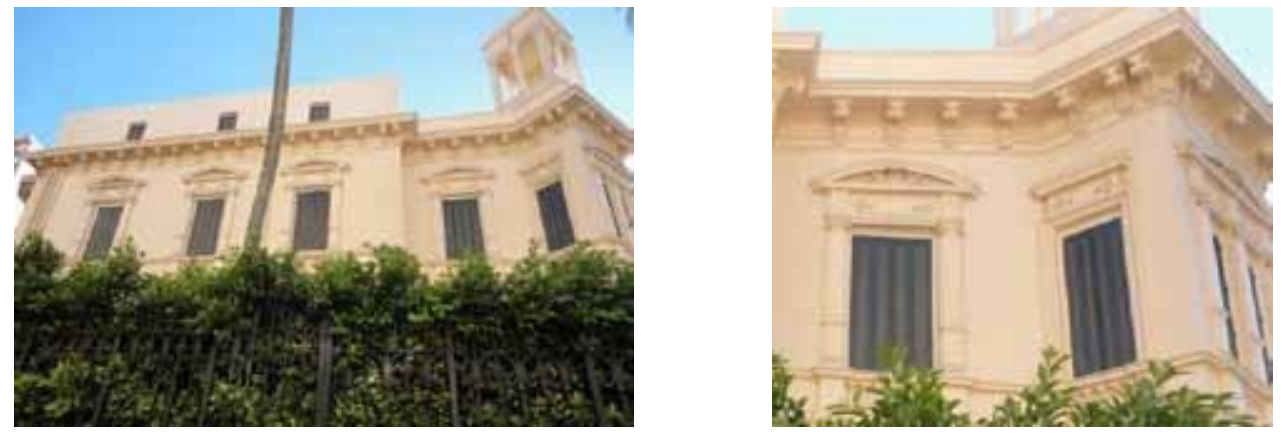

Fig. 8 : Ornamental details of a Neoclassic style villa facade; where windows surrounded with ionic capitals pilasters and raised panels topped with an arched pediment with scrolling foliage, cornice with repeated voluted brackets, stone like wall finishing. (Latin District) 

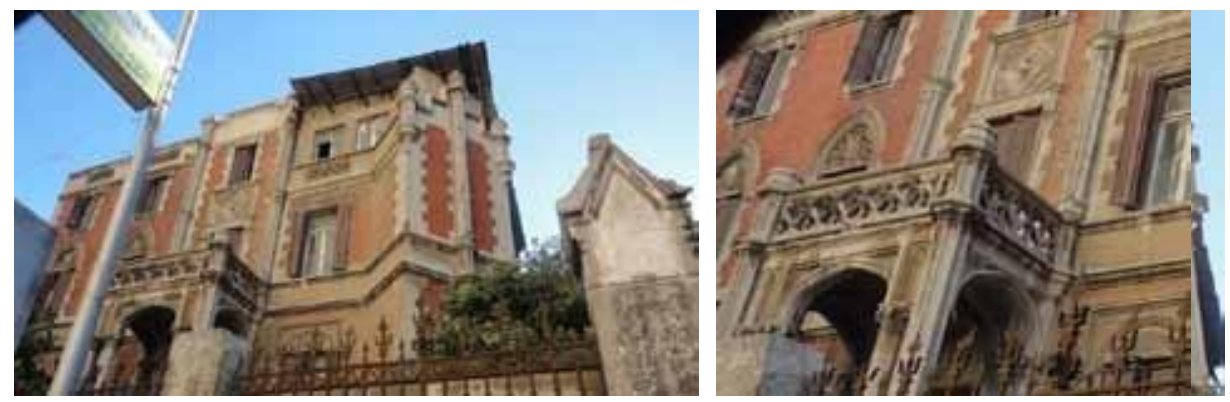

Fig. 9: Ornamental details of a Gothic revival style villa facade; with a porch of gothic columns, vertical gothic pilasters, gothic pointed transom over the entrance, a label around windows, balconies grills and parapet with gothic ornaments, quoins on corner sides, rectangular andflattened pointed arches panels with gothic bas relief motifs, urns on top edges. (Latin District)
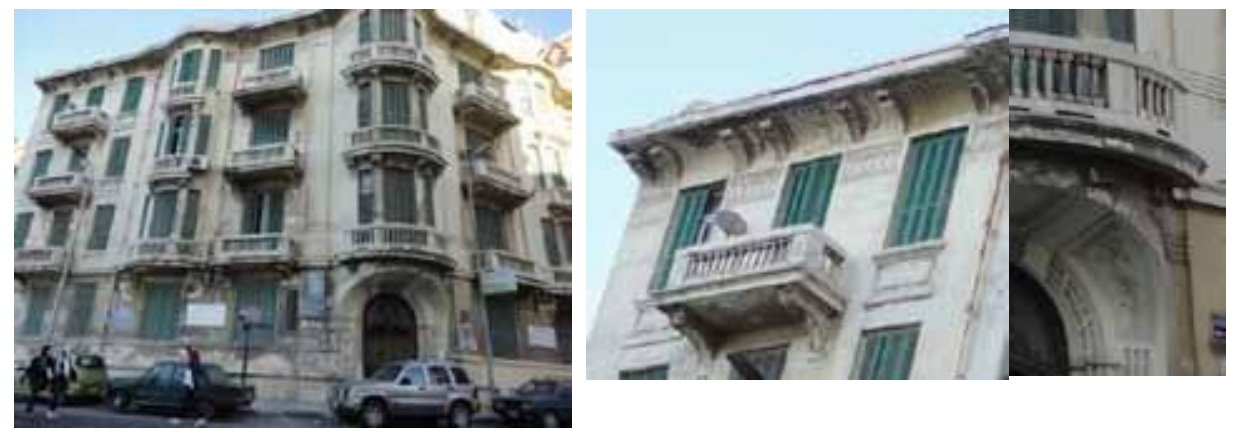

Fig. 10 : Ornamental details of an Eclectic Style residential building façade; the main entrance at the corner with classic panels and decorative foliage, balcony balustrades of repetitive ionic columns, brackets with volutes supporting balconies, a frieze surrounding the top of the building and another at the middle with a bas relief geometric pattern. (Azaritah District) 

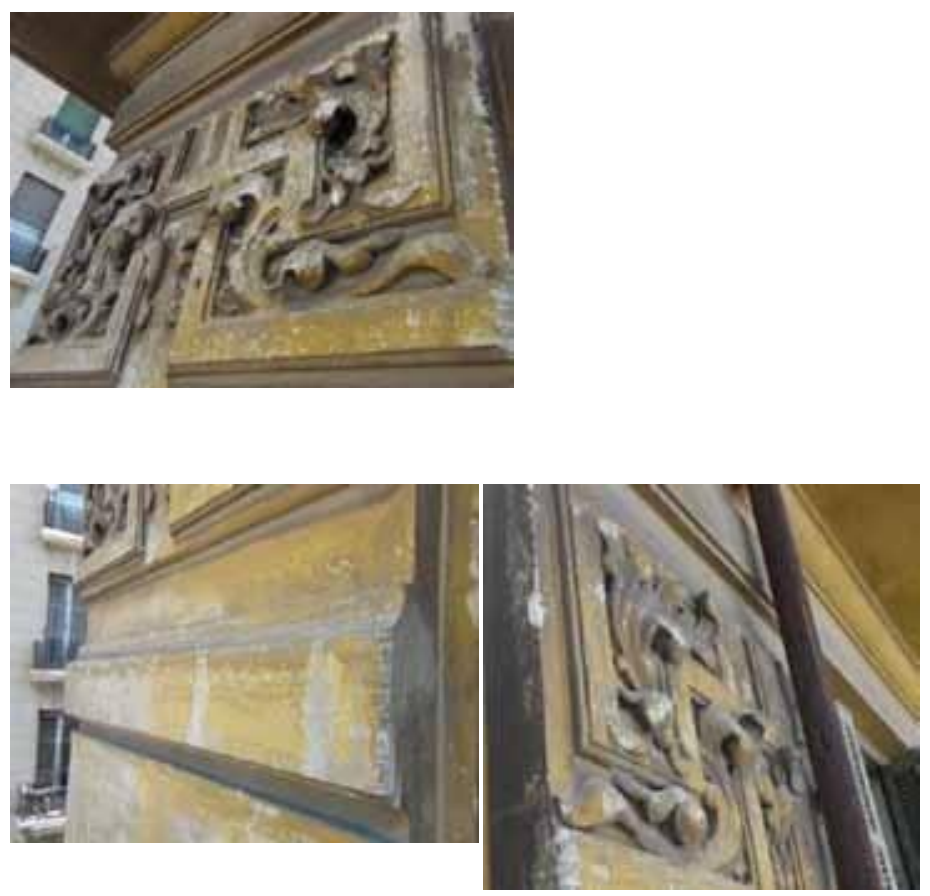

Fig.11: Close up ornamental stucco bas relief detail of classical influenced building facade frieze with foliage embraced into Greek Key decorative border identifying infinity and unity. (Residential building in Fouad St.)
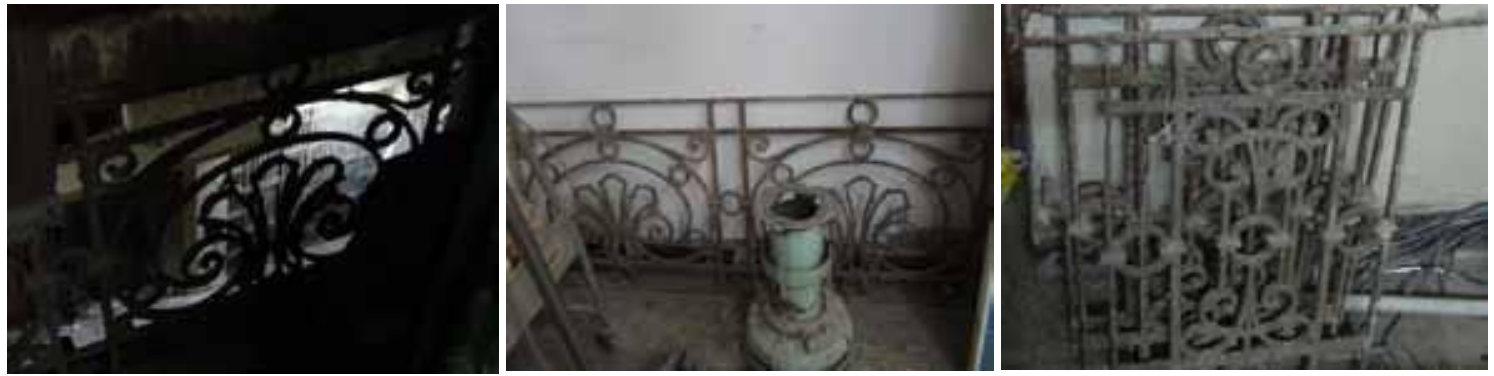

Fig. 12: Ornamental detail of forged iron (fer forge) balcony grills with scrolls, circular and anthemion leaf patterns, wide spread classical rhythmical repetition of classical motifs.(Residential building in Fouad St.) 


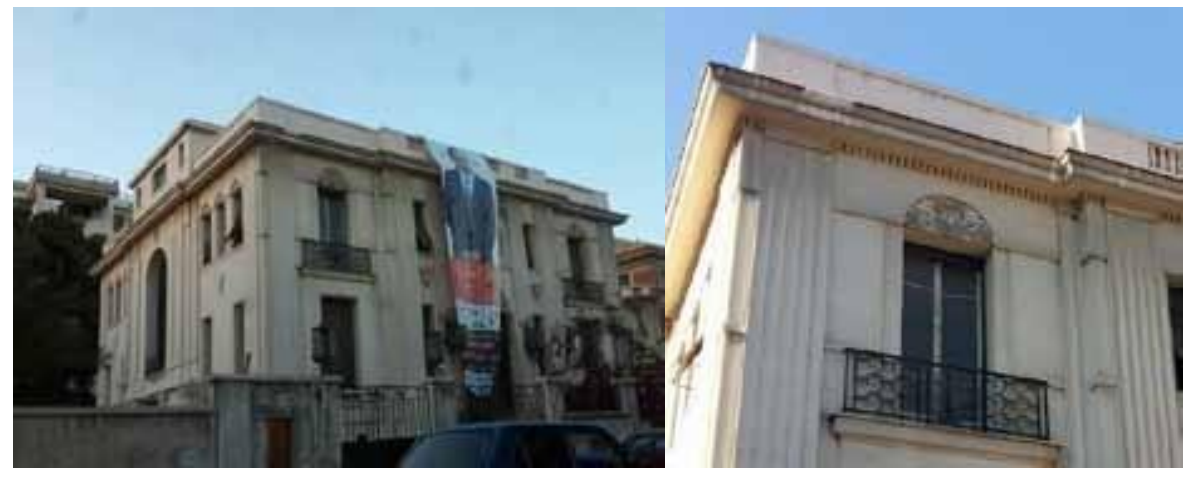

Fig.13 : Ornamental details of an Art Deco Style villa facades, with a mix of different styles; vertical pilasters with shallow volutes and a minimal capital, accentuates gracefulness of lines, semicircular panels over windows and doors with decorative bas relief ornaments of gargoyles heads and geometric repeated patterns of foliage like motifs, dentil ornament surrounding thetop, gargoyles heads symbolizing guardians, forged iron (fer forge) balcony grills with scroll patterns, classical balustrades on parts of the parapet. (Soliman Yousri St.- Latin District)
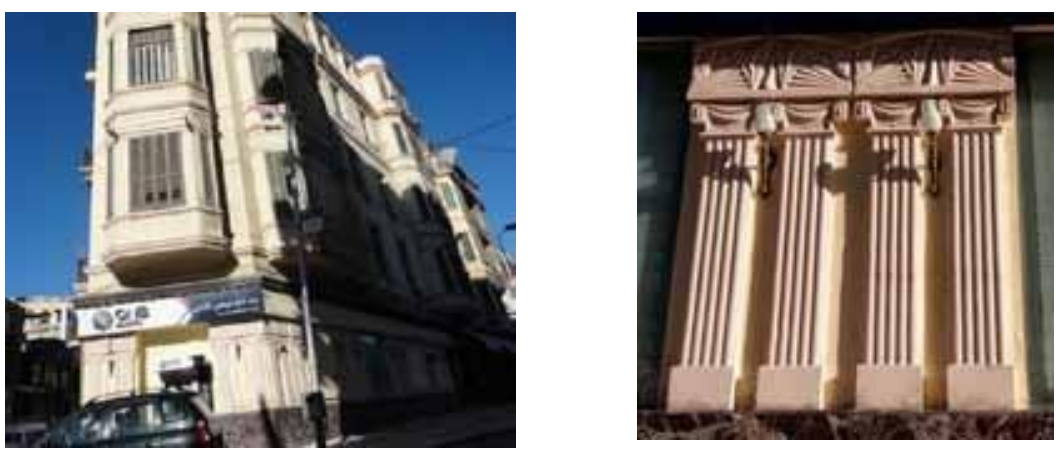

Fig. 14: Ornamental details of Art Deco Style residential building façade; the ground level has distinctive decorative sets of pilasters with a rectangular base and capitals of volutes and festoons, with a geometric radiating ornamental plate above it. (Fouad St.) 

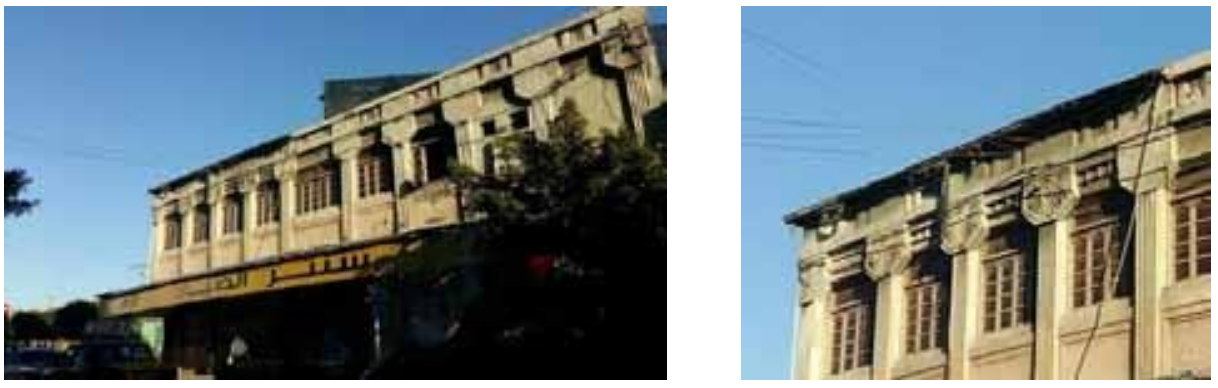

Fig. 15 : Ornamental details of an Art Deco Style building facade, with an arcade of Greek influenced fluted pilasters with capitals of volutes and anthemion leaf, an entablature with an abstract of metope and triglyph, defining the principle of recurrence and rhythm. (Soliman Yousri St.- Latin District)

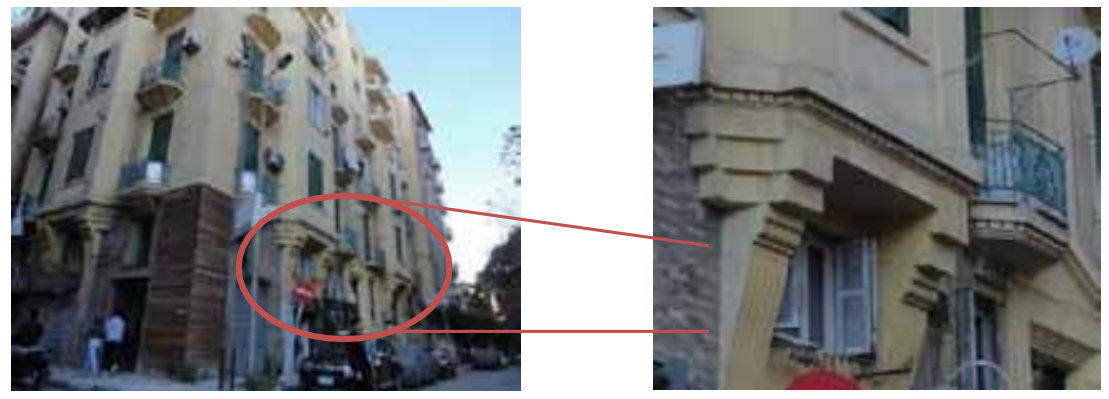

Fig. 16: Ornamental details of an Art Deco Style residential building, Lintel support of stepped angular ornaments and dentils with brackets of classic influences, balcony grills of abstractanthemion leaf, united by a desire to be modern. (Manshia District)

\section{6- Conclusions and Recommendations:}

- Alexandrian ornaments of heritage buildings especially those of antiquity must be well preserved codified and easily reproduced.

- Alexandrian ornaments of heritage buildings may best serve as landmarks and aids in districts distinction through the city.

- The importance of studying and considering the cultural and symbolic significance of ornament and its subsequent reinvention in order to identify and understand the range of ornamental design principles used in previous times which signifies the transformationsof eras.

- Recreating ornaments and motifs according to the study recommending 
INTERNATIONAL JOURNAL OF

MULTIDISCIPLINARY STUDIES IN ARCHITECTURE AND CULTURAL

HERITAGE

specialists work on these elements within the principles of rhythm, in order to reach a contemporary ornamentation of building.

- Suggesting new contemporary architectural elements, in the future, as a practical application, to borrow those forms of beauty from our past.

- We should regard our inheritance, not blindly following them but employing them simply as guides to find the true paths to grant the unity and identity of the future constructed buildings.

- Ornaments and motifs are strong elements of design for reminiscences of nostalgic feelings and an Impact of forming our personal memories.

- It is important to preserve heritage buildings, trying to reuse or rehabilitate most of them into public use functions such as cultural centers, for the next generations to understand and appreciate the meaning of antiquity and to preserve the identity of Alexandria.

\section{$\underline{\text { References }}$}

Awad, Mohamed (2008), Italy in Alexandria: Influences on the Built Environment AlexandriaPreservation Trust 2008 - Dar El Koutab.

Biedermann, Hans (1992), Dictionary of Symbolism, Cultural icons and the meanings behindthem, New York, Oxford.

Davies, Paul and Hemsoll, David, (2013) Renaissance and Later Architecture and Ornament -Royal Collection Trust, England.

Fletcher, Banister (1999) A History of architecture, CBS Publishers,

England.Jones, F. Bedford (1856), The Grammar of Ornament, Day

and Son, London.

Necipoğlu, Gülru , Payne, Alina and others (2016) - Histories of Ornament: From Global to Local - Princeton University Press, England.

Trilling, James (2001), The Language of Ornament (World of Art) - Thames \& Hudson, EnglandTrilling, James (2002), Ornament: A Modern Perspective - Samuel and Althea Stroum Books - University of Washington Press, Canada. (First edition).

Yarwood, Doreen (1994), The Architecture of Europe - Classical Architecture 1420

- 1800(Vol.3), Batsford Ltd, London.

\section{World Wide Web:}


INTERNATIONAL JOURNAL OF

MULTIDISCIPLINARY STUDIES IN ARCHITECTURE AND CULTURAL

HERITAGE

http://cavitt.eurekausd.org/documents/Parents/PTC/Art\%20Docent\%20Presentations

18th\%20Gra de/Revised_Oct2015 Neoclassical_Architecture Presentation.pdf

http://www.eptort.bme.hu/doc/egyeb/bekacomb.pdf

http://www.phs.poteau.k12.ok.us/williame/APAH/readings/Neoclassical\%20and\%20Romanti c\% 20Architecture, \%20Janson.pdf

http://www.virtualclassrooms.com/outlines/cusack larkland.pdf

http://yadda.icm.edu.pl/yadda/element/bwmeta1.element.baztech-1075fb48-

$\underline{\text { 363d-4826-a816- 3c3ce091ffc5/c/ek B-04 PiF21 Kazantseva Ponkalo.pdf }}$

https://5blucreziocaro.wikispaces.com/file/view/CARO+Belotti+Neoclassical+Architecture.p df

https://alamy.com/searchimages/Antiqua Print Gallery / Alamy

Stock Photo/2017

https://jhabreaq.files.wordpress.com/2010/01/neoclassical-

architecture.pdf

https://prezi.com/ae7paxw87n4o/classical-neoclassical-architecture/

https://www.researchgate.net/publication/303863310_Democracy_in_Architecture_The_Revi

$\underline{\mathrm{val}}$

_of_Ornament

https://www.strombergarchitectural.com/images/materials/glossary/stromberg-architecturalfull- glossary.pdf

Note: Photos Captured by Author

Received: February 15, 2018

Accepted: April 20, 2018 